\title{
PENGARUH PROSES OIL TERHADAP TEGANGAN PUTUS \\ DAN PERPANJANGAN PUTUS KARET UNTUK KOMPONEN \\ POMPA AIR TANGAN
}

Oleh : Siti Rochani, Luciawati Sunarjo

\section{ABSTRACT}

The objective of this research is to know influence of process oil to the physical properties tensile strength and elongation at break of rubber compound for hand water pump. Vulcanized rubber makes from Rubber Smoke Sheet (RSS) and Styrene Butadiene Rubber (SBR 1502) as raw material. Ingredient which added to raw material were Paraffin Wax, Stearic Acid, $\mathrm{ZnO}, \mathrm{CaCO}$, Carbon Black, Process Oil, CBS, TMT, AOSP and Sulphur. Raw material rubber and ingredient were compounded in a two roll mill and formed to slab by hydraulic press at temperature $150{ }^{\circ} \mathrm{C}$ and pressure $150 \mathrm{~kg} / \mathrm{cm} 2$. It should be carry out by varrying process oil $3-9$ part by weight raw material. The compound was tested tensile strength and elongation at break. The result of this research indicated that process oil (X1) and tensile strength (Y1) have regression equation as $\mathrm{Y} 1=235,697-8,33 \mathrm{X}$ (corelation coeffisien $=0,72$ ) while process oil and elongation at break has regression equation as $\mathrm{Y} 2=251,64+12,75 \mathrm{X}$ (corelation coeffisien $=0,97$ ).

\section{INTISARI}

Penelitian ini bertujuan untuk mengetahui pengaruh proses oil terhadap sifat fisis tegangan putus dan perpanjangan putus vulkanisat karet untuk pompa air tangan Vulkanisat karet untuk komponen pompa air tangan dibuat dari bahan baku Rubber Smoke Sheet (RSS) dan Styrene Butadiene Rubber (SBR 1502) ditambah ingredieningredien antara lain Paraffin Wax, Asam stearat, $\mathrm{ZnO}, \mathrm{CaCO}$, Carbon Black, Proses Oil, CBS, TMT, AOSP dan sulfur. bahan-bahan tersebut diatas dikomponding pada sebuah alat two roll mill. Kompon yang dihasilkan dibuat menjadi bentuk slab dengan menggunakan hydraulic press pada suhu $150{ }^{\circ} \mathrm{C}$ dan tekanan $150 \mathrm{~kg} / \mathrm{cm} 2$. Kompon karet untuk komponen pompa air tangan dibuat dengan memvariasikan proses oil 3 sampai 9 bagian berat bahan baku karet. Pengujian yang dilakukan terhadap kompon tersebut adalah uji tegangan putus dan perpanjangan putus. Data hasil pengujian menunjukkan bahwa antara proses oil $(\mathrm{X})$ dengan tegangan putus (Y1) menunjukkan ada persamaan regresi sebagai berikut : $\mathrm{Y} 1=235,697-8,3 \mathrm{Xl}$ (koefisien korelasi $=0,72$ ). Sedangkan antara proses oil dengan perpanjangan putus $(\mathrm{Y} 2)$ mempunyai persamaan regresi $\mathrm{Y} 2=251,64+12,75 \mathrm{X}$ (koefisien korelasi $=0,97$ ). 
Bahan pelunak atau softener juga disebut "physical softener atau physical usticizer". Walaupun bahan ini tidak bereaksi secara kimia dengan karet, namun bahan tersebut berpengaruh terhadap sifat kompon dan vulkanisatnya. Beberapa hal yang penting sebagai akibat dari penggunaan bahan pelunak dalam proses pembuatan barang karet antara lain :

1. meningkatkan plastisitas kompon

2. membantu mempercepat pencampuran pigmen

3. mengurangi temperatur pencampuran

4. mengurangi kemungkinan kompon lengket ke mill

5. meningkatkan daya lengket sesama kompon

6. memperlancar proses ekstrusi dan molding

7. mengurangi pemakaian energi

8. bersifat sebagai pelumas pada jaringan vulkanisat

9. memperbaiki sifat vulkanisat

Istilah peptiser, plasticizer, softener dan extender sangat berhubungan erat dan bisa saling mengganti. Peptiser digunakan untuk menaikkan efisiensi mastikasi karet seperti untuk menaikkan kecepatan pemutusan rantai molekul, khususnya untuk karet alam. Penggunaan peptiser dalam kompon, yang normal kurang dari $0,5 \mathrm{phr}$ untuk karet alam, sedangkan untuk karet sintetis digunakan lebih banyak lagi. Peptiser ditambahkan pada saat awal mastikasi, sedangkan ingredient yang lain ditambahkan setelah selesainya proses mastikasi. Beberapa peptiser cocok untuk mastikasi dalam internal mill dan yang lain cocok digunakan pada open mill. Peptiser tidak mempengaruhi sifat vulkanisat yang dihasilkan.

Proses oil adalah petroleum yang didasarkan minyak mineral. Penggunaan proses oil dalam kompon berkisar antara 5-10 phr. dalam proses komponding proses bil berfungsi menurunkan viskositas dan memudahkan penggabungan filler. Kekerasan kompon akan berkurang atau menurun tc gantung jumlah dan grade oil yang dipergunakan. Proses oil dibedakan menjadi 3 yaitu aromatik oil, naphtenic oil dan paraffinic oil. Aromatic oil mempunyai sifat memproses (process ability) yang baik, namun mempunyai efek yang buruk karena bisa menyebabkan pengotoran (staining). Paraffinic oil mempunyai sifat kebalikan dari aromatic oil yaitu kemampran proses kurang bagus namun efek terhadap pengotoran kecil. Sedangkan naphtenic oil mempunyai sifat antara aromatic oil dan paraffinic oil.

Beberapa macam plasticizer beserta sifat dan kegunaannya adalah seperti tersebut tibawah ini :

Majalah Barang Kulit, Karet dan Plastik

\begin{tabular}{|l|l|}
\hline \multicolumn{1}{|c|}{ Nama } & \multicolumn{1}{|c|}{ Sifat/kegunaan } \\
\hline Aromatic Oil & $\begin{array}{l}\text { Menyebabkan noda, stabilitas warna berkurang, } \\
\text { ketahanan terhadap aging berkurang. Cocok } \\
\text { untuk karet alam dan sintetis (kecuali butyl) }\end{array}$ \\
Paraffinic Oil & $\begin{array}{l}\text { Cocok untuk karet butyl. Efektivitas sebagai } \\
\text { processing aid kecil. Sedikit memberikan efek } \\
\text { noda warna. Tahan terhadap aging. } \\
\text { Naphtenic Oil }\end{array}$ \\
Pine Tar & $\begin{array}{l}\text { Mempunyai sifat antara aromatic oil dan } \\
\text { paraffinic oil. } \\
\text { Untuk karet alam. Bersifat asam. Penggunaan }\end{array}$ \\
HydrocarbonWax & $\begin{array}{l}\text { 3-7 phr. Membantu masuknya carbon black } \\
\text { dalam karet. } \\
\text { Untuk proses ekstrusi, pemakaian sampai } \\
\text { dengan 0,5\%, jika terlalu banyak menyebabkan } \\
\text { blooming. } \\
\text { Untuk softener karet butyl, penggunaan lebih } \\
\text { dari } 5 \% . \\
\text { Entuk karet sintetik } \\
\text { Asam lemak dari derivatifnya } \\
\text { Tahan aging } \\
\text { Membantu dispersi filler dalam karet, } \\
\text { mencegah lengketnya karet pada rol. }\end{array}$ \\
\hline
\end{tabular}

Vol. XII No. 22 Th. $1996 / 1997$ 


\begin{tabular}{|l|l|}
\hline Bitumen & $\begin{array}{l}\text { Berfungsi sebagai softener dan filler } \\
\text { Penggunaan 5-20 phr } \\
\text { Membantu pencampuran filler, merendahkan } \\
\text { suhu proses dan mengurangi schorching. } \\
\text { Coumaron resin }\end{array}$ \\
Untuk karet sintetis, memperbaiki kenampakan \\
pada permukaan \\
Vegetable Oil
\end{tabular}

\section{MATERI DAN METODE}

1. Materi

Materi penelitian meliputi bahan baku, bahan pembantu dan peralatan yang digunakan dalam penelitian

a. Bahan baku

- karet alam

- Karet sintetis

Rubber Smoked Sheet ( RSS I)

b.Bahan pembantu

Styrene Butadiene Rubber (SBR 1502)

Prose Oil, $\mathrm{CaCO} 3$, Carbon Black, Asam Stearat, $\mathrm{ZnO}$, Parafinic Wax, TMT, CBS, AOSP dan Sulfur

c. Peralatan

- Alat-alat proses

- Alat uji

timbangan, pisau potong, krus porselin, two roll mill, cetakan kompon, hydraulic press, stop watch, lembaran aluminium, curometer.

alat uji curing time

alat uji tegangan putus

2. Metode Penelitian

a. Formulasi Bahan

Kompon karet untuk komponen pompa air tangan dibuat dengan formulasi sebagai berikut :

\begin{tabular}{|l|l|}
\hline \multicolumn{1}{|c|}{ Bahan } & \multicolumn{1}{c|}{ Bagian berat } \\
\hline RSS & 80 \\
SBR 1502 & 20 \\
CaCO3 & 15 \\
Carbon Black & 50 \\
Asam Stearat & 1,5 \\
ZnO & 4 \\
Proses Oil & $3,4,5,6,7,8,9$ bagian \\
(bervariasi) & \\
Paraffin Wax & 1 \\
TMT & 0,25 \\
AOSP & 1 \\
CBS & 1 \\
Sulfur & 2 \\
\hline
\end{tabular}

b. Proses Pembuatan Kompon Karet untuk Pompa Air Tangan

- Bahan ditimbang sesuai dengan formulasi yang ditetapkan.

- Karet alam ( RSS ) dimastikasi didatam two roll mill, kemudian ditambah SBR 1502 digiling, masukkan parafin wax giling sampai plastis. Suhu two roll mill dijaga paling tinggi $70^{\circ} \mathrm{C}$.

- Tambahkan Asam Stearat dan $\mathrm{ZnO}$, kemudian Carbon Black dan proses oil, digiling lagi sampai homogen. Sesudah itu tambahkan PBN, CBS dan TMT. Terakhir masukkan sulfur, digiling lagi hingga homogen.

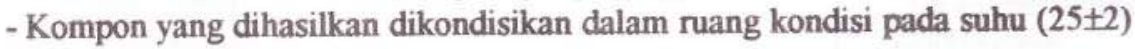
${ }^{\circ} \mathrm{C}$, kelembaban 65 \% selama kurang lebih 24 jam.

- Setelah itu dilakukan uji cure time untuk mengetahui waktu optimum kemasakan karet.

- Kompon dibuat bentuk slab dengan menggunakan alat Hidrolik Press pada suhu $150^{\circ} \mathrm{C}$, tekanan $150 \mathrm{~kg} / \mathrm{Cm}$ dengan waktu yang disesuaikan dengan hasil uji Cure time.

c. Pengujian tegangan putus dan perpanjangan putus

Pengujian dilakukan dengan menggunakan alat Uji Tegangan Putus. Potong cuplikan dengan bentuk dayung ( dumbell ) memakai pisau pons.

Beri tanda dua garis sejajar pada cuplikan berjarak $2 \mathrm{Cm}$ simetris ditengahtengah dayung.

Vol. XII No. 22 Th. 1996/1997 
Ukur lebar dan tebal cuplikan kemudian pasang pada alat sehingga jarak antara kedua jepitan $50 \mathrm{~mm}$. Penarikan dikerjakan dengan kecepatan $25 \pm 1 \mathrm{Cm} / \mathrm{menit}$ sampai cuplikan putus.

\section{Perhitungan :}

Tegangan putus: $\frac{\mathrm{F}}{\mathrm{t} \times \mathrm{w}} \mathrm{kg} / \mathrm{Cm} 2$

Perpanjangan putus: L1 - Lo $\times 100 \%$ Lo

\section{Keterangan}

F

wo

L1

\begin{abstract}
beban yang diperlukan untuk menarik cuplikan sampai putus, $\mathrm{kg}$ tebal cuplikan, $\mathrm{Cm}$
\end{abstract}

lebar cuplikan, $\mathrm{Cm}$

panjang mula-mula cuplikan antara 2 tanda garis

panjang cuplikan antara 2 tanda garis, pada waktu putus

\section{HASIL PENELITIAN DAN PEMBAHASAN}

Sifat fisis tegangan putus

Hasil uji sifat fisis tegangan putus kompon karet untuk komponen pompa air tangan dengan variasi pemakaian proses oil $3 ; 4 ; 5 ; 6 ; 7 ; 8$ dan 9 bagian dapat dilihat pada lampiran 1 .

Dari data hasil uji tersebut dibuat grafik hubungan antara tegangan putus dengan jumlah proses oil

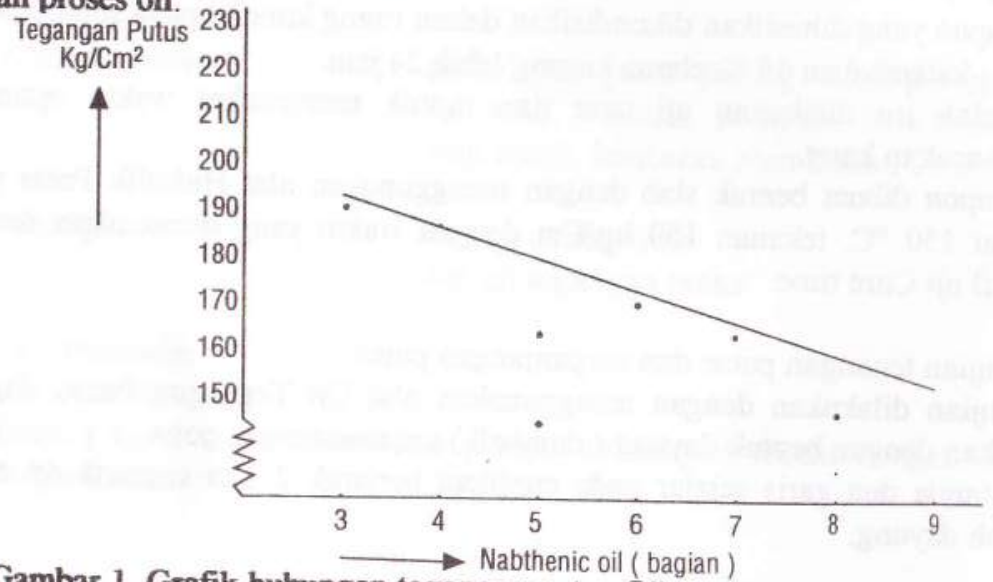

Gambar 1. Grafik hubungan tegangan putus ( $(Y)$ dengan proses oil $(\mathrm{X})$.

Majalah Barang Kulit, Karet dan Plastik
Persamaan regresi untuk garis lurus adalah $\mathrm{Yl}=\mathrm{a}+\mathrm{bX}$. Setelah dihitung didpatkan nilai $a=235,69$ dan nilai $b=-8,33$, sehingga persamaan regresinya menjadi $Y=235,69-8,33 X$ (untuk $X=3 \mathrm{~s} / \mathrm{d}$ 9). Nilai koefisien korelasi ( $\mathrm{r}$ ) untuk persamaan garis tersebut adalah 0,72 . Garis regresi terlihat cenderung semakin menurun dengan bertambahnya nilai X (jumlah proses oil). Yang berarti bahwa nilai tegangan putus kompon semakin turun dengan naiknya jumlah proses oil.

Hal ini disebabkan karena dengan semakin banyak jumlah proses oil, karet akan semakin melunak karena berkurangnya panjang molekul karet, sebagai akibat dari pemutusan ikatan rangkap karet. Karena panjang molekul karet semakin berkurang, maka tegangan putus kompon semakin rendah.

\section{Sifat fisis perpanjangan putus}

Data hasil uji sifat fisis perpanjangan putus dapat dilihat pada lampiran 2 Dari data hasil uji tersebut dibuat grafik hubungan antara perpanjangan putus dengan jumlah proses oil.

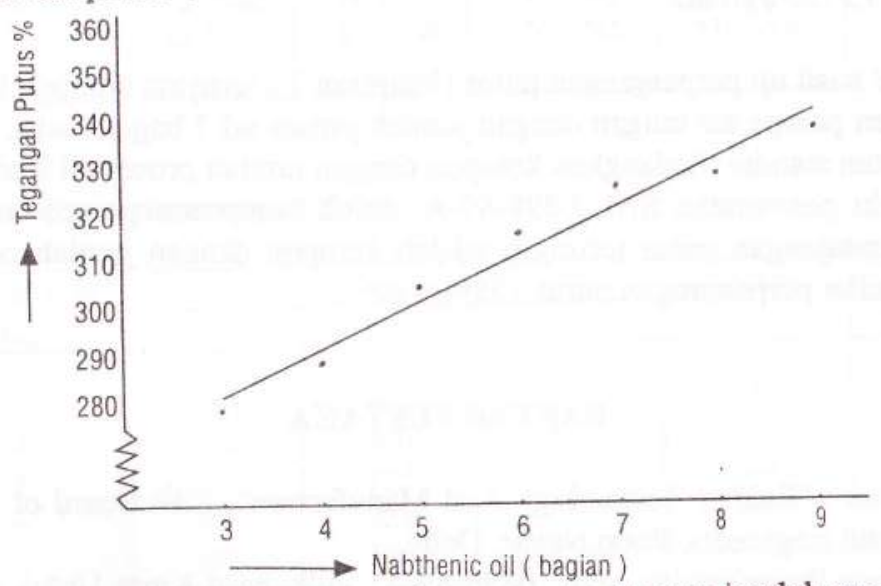

Grafik 2. Hubungan antara perpanjangan putus dengan jumlah proses oil

Grafik berbentuk garis lurus dengan nilai konstanta $a=251,64$ dan $b=12,75$, sehingga persamaan regresi menjadi $Y=251,64+12,75 X$. Koefisien korelasi dari persamaan garis tersebut adalah 0,97 . Dari grafik tersebut diatas ternyata ada persakin naik nilai perpanjangan putus dengan bertambahnya kecenderungan semakin naik nilai perfos oil yang berfungsi juga sebagai proses oil. Hal ini disebabkan kanyak proses oil maka karet akan semakin pelunak. Oleh karena itu semakin banyak proses in tinggi dan tegangan putusnya semakin rendah

Vol. XII No. 22 Th. 1996/1997 


\section{KESIMPULAN} Berdasarkan hasil penelitian pembuatan kompon karet untuk komponen pompa air
angan dapat disimpulkan bahwa :

- Jumlah penggunaan proses oil sangat berpengaruh terhadap sifat fisis tegangan putus dan perpanjangan putus, dengan persamaan regresi $Y 1=235,69-8,33 X$ putus, $X=$ jumlah proses oil $)$.

Hasil uji tegangan putus seperti terlihat pada tabel dalam lampiran 1. dengan bagian berat proses oil $3 \mathrm{~s} / \mathrm{d} 9$ bagian memenuhi persyaratan SNI. 0898-89-A : "Vulkanisat Karet Untuk Komponen Pompa Air Tangan". Nilai tegangan putus putus $229,2125 \mathrm{~kg} / \mathrm{cm} 2$.

Dari tabel hasil uji perpanjangan putus (lampiran 2.) ternyata kompon karet untuk komponen pompa air tangan dengan jumlah proses oil 3 bagian tidak memenuh persyaratan standar. Sedangkan kompon dengan jumlah proses oil $4 \mathrm{~s} / \mathrm{d} 9$ bagian memenuhi persyaratan SNI. 0898-89-A, untuk komponen pompa bagian diam nilai perpanjangan putus tertinggi adalah kompon dengan jumlah proses oil 9 bagian (nilai perpanjangan putus $358 \%$ ).

\section{DAFTAR PUSTAKA}

Anomimous : "Rubber Technology And Manufacture", SBP Board of Consultant and Engineers, Roop Nagar, Delhi. Pepartemen Perindustrian SNI . 0898-89-A, Vulkapisat Karet Untuk Komponen
Pompa Air Tangan. larry Baron: "Modern Rubber Chemistry", D Van Nostrand Company Inc, New
York, 1948.

Iurray R Spiegel, Phd : Schaum'c Out Line of Theory and Problems "Statistic" in Arizal "Rub Graw Hill International Book Company, Singapore.

Peningkatan Teknologi Karet Produksi Dalam Negeri", Lokakarya Parafinic.
Lampiran 1.

Tabel data hasil uji tegangan putus kompon karet untuk komponen pompa air tangan $(\mathrm{kg} / \mathrm{cm} 2)$

\begin{tabular}{|c|c|c|c|c|c|}
\hline \multirow{2}{*}{$\begin{array}{c}\text { Naphtenic oil } \\
\text { (Bag.) }\end{array}$} & \multicolumn{3}{|c|}{ Ulangan } & Total & Rata-rata \\
\cline { 2 - 4 } 3 & 1 & 2 & 3 & & \\
\hline & 194,5730 & 207,8811 & 216,4782 & 618,9323 & 206,3108 \\
4 & 216,9748 & 232,9300 & 237,7328 & 687,6376 & 229,2125 \\
5 & 154,3346 & 204,3316 & 166,2835 & 524,9497 & 174,9832 \\
6 & 198,8792 & 160,7526 & 188,8444 & 548,4762 & 182,8254 \\
7 & 191,2172 & 141,5894 & 188,6425 & 521,4491 & 173,8164 \\
8 & 162,7482 & 160,1765 & 135,2642 & 458,1889 & 152,7296 \\
9 & 184,9970 & 183,6898 & 170,9782 & 539,6650 & 179,8883 \\
& & & & & \\
\hline
\end{tabular}

lampiran 2 .

Tabel hasil uji perpanjangan putus, $\%$

\begin{tabular}{|c|c|c|c|c|c|}
\hline \multirow{2}{*}{$\begin{array}{c}\text { Naphtenic oil } \\
\text { (Bag.) }\end{array}$} & \multicolumn{3}{|c|}{ Ulangan } & Total & Rata-rata \\
\cline { 2 - 4 } & 1 & 2 & 3 & & \\
\hline & & & & & \\
4 & 290 & 270 & 290 & 850 & 283 \\
5 & 300 & 300 & 300 & 900 & 300 \\
6 & 315 & 325 & 325 & 965 & 322 \\
7 & 340 & 325 & 330 & 995 & 332 \\
8 & 375 & 350 & 350 & 1050 & 350 \\
9 & 375 & 320 & 360 & 1055 & 352 \\
& & 350 & 350 & 1075 & 358 \\
\hline
\end{tabular}

